\title{
Identifying the Cognitive Needs of Visitors and Content Selection Parameters for Designing the Interactive Kiosk Software for Museums
}

\author{
Dinesh Katre $^{1}$ and Mandar Sarnaik ${ }^{2}$ \\ ${ }^{1}$ Group Coordinator, Human Centred Design and Computing, C-DAC, Pune \\ dinesh@cdac.in \\ ${ }^{2}$ Student of M. Des. In Interaction Design, Industrial Design Centre, IIT Bombay, Mumbai \\ mandar.sarnaik@iitb.ac.in, mandar.sarnaik@gmail.com
}

\begin{abstract}
This research presents the findings of contextual interviews, visitor survey and behavioural study that were carried out in Indian museums. It originates from the hypothesis that the museum exhibits are unable to express their relevance, historical significance and related knowledge to satisfy the curiosity of visitors. Our objective is to identify the cognitive needs of museum visitors and the content selection parameters for designing the interactive kiosk software, which is expected to be set up in every thematic gallery of the museum. The kiosk software is intended to offer higher level of engaging and learnable experience to the museum visitors. The research involved participation of $100+$ visitors in Indian museums. The access restrictions and constraints of museums cause cognitive deprivation of visitors and compromise the quality of experience. Therefore, the interactivity, animations and multimedia capabilities of kiosk software must be focused on overcoming these limitations.
\end{abstract}

Keywords: Visitor-centred design approach, Museums, Interactive kiosk software, Contextual interviews, Survey, Questionnaire, Social behavior, Cognitive needs, Content selection parameters, Visitor / user experience.

\section{Introduction}

This research is carried out for an ongoing project, which involves design and development of touch screen based kiosk software, which is to be hosted in each thematic gallery of Prince of Wales Museum, Mumbai, India. The potential users of the proposed kiosk software are basically the museum visitors that include school children, tourists and other diverse categories of people. Therefore, it is quite difficult to define the attributes of museum visitors.

\subsection{Scope}

As per the scope defined for this project, each kiosk software has to present interesting information about the theme of gallery, highlight the historical significance of artefacts, provide interactive games and animations to make it an engaging and learnable experience for the visitors. On the whole, the kiosk software should provoke the 
interest of visitors about history and motivate them to explore historical exhibits displayed in each gallery. It should also raise the level of their appreciation of historical artefacts. It is decided to present the information in Hindi, Marathi and English languages to address the communication requirements of regional, national and international visitors. Each interactive application is desired to be not more than 20 mnts in run-time duration, if one was to go through all the information, so as to avoid crowding before the kiosk.

\subsection{Research Questions}

Museums are free-choice learning or informal educational environments. Enormous variability in both the environment and the audience makes it very challenging for the researchers to make sense of what visitors learn [1]. Therefore, before starting to design the interactive kiosk software, it was essential for us to seek certain design directions from the museum visitors. We had following questions in our mind, which are based on our hypothesis that the museum exhibits are unable to express their relevance, historical significance and related knowledge to satisfy the curiosity of visitors.

- Considering the existing non-interactive exhibits and supplementary information displayed in museums in the form of labels and posters, what new things 'interactive kiosk software' should offer?

- What are the cognitive needs [12] of museum visitors which must be addressed for developing proper understanding of the historical artefacts?

- What parameters should be applied for selecting the content for inclusion in the kiosk software?

Our primary goal behind this project is to create an engaging and learnable visitor / user experience through the interactive kiosk software.

\subsection{Related Work}

We have referred the existing research on usability of public access systems like kiosks and environmental psychology both. The brief overview of this study is presented below.

The key design principles for kiosk based public access systems like immediate attraction, immediate learning, immediate engagement and immediate disengagement are very relevant and useful in our project [10]. The proposed touch screen kiosk is a midway approach if compared with the tangible interactive installations [7] and low tech interactive option already explored in the context of museums [11]. The case study of conversational familial collaboration and relationships through handheld device in the context of museums are also found useful for our study of social behavior of museum visitors [8]. Advanced technological experiments involving augmented reality [6] with mobile multimedia guide and personalization of visitor experience provide broad guidelines that are relevant to our project [5]. The doctoral study on "visitor behavior, interrelationships of adult visitors' view of learning experience" in the museums provides the 5P model of museum learning which includes Person, Purpose, Process, People and Place as its main aspects [9]. Wilson [12] has already stated the importance of physiological, affective and cognitive needs pertaining to the information seeking behavior of people in an environment. Cognitive 


\begin{tabular}{|llll|}
\hline V1 & Visitor Name & & \\
\hline & 26yrs & & \\
\hline & Jaipur & & \\
\hline & Degree:Law / taxation & & \\
\hline V1-1 & $\begin{array}{l}\text { I came to the museum to see } \\
\text { and compare today's lifestyle } \\
\text { with the olden days }\end{array}$ & $\begin{array}{l}\text { Visitor } \\
\text { statement }\end{array}$ & High \\
\hline V1-2 & $\begin{array}{l}\text { To know what food, clothing } \\
\text { etc. our forefathers had 1000 } \\
\text { years before }\end{array}$ & $\begin{array}{l}\text { Visitor } \\
\text { statement }\end{array}$ & High \\
\hline V1-3 & $\begin{array}{l}\text { Visitor has been exposed to a } \\
\text { lot of historical monuments and } \\
\text { stories by virtue of his native } \\
\text { place (Jaipurl Rajasthan which } \\
\text { has a lot of historical } \\
\text { background }\end{array}$ & & \\
\hline
\end{tabular}

\begin{tabular}{|c|c|c|c|c|}
\hline $\begin{array}{c}\text { Visitor } \\
\text { no. }\end{array}$ & Gender & Age & From & Qualification \\
\hline 1 & Male & 26 yrs & Jaipur & $\begin{array}{l}\text { Degree in } \\
\text { Law/taxation }\end{array}$ \\
\hline 2 & Male & 33 yrs & Thailand & Energy scientist \\
\hline 3 & Female & 23 yrs & Pune & Hardware professional \\
\hline 4 & Female & $20 \mathrm{yrs}$ & Nagpur & Engineering student \\
\hline 5 & Male & 25 yrs & Mumbai & PG student \\
\hline 6 & Male & $27 \mathrm{yrs}$ & Pune & PG student \\
\hline 7 & Male & $30 \mathrm{yrs}$ & Ahmedabad & Tabla|player \\
\hline 8 & Female & $28 \mathrm{yrs}$ & Germany & Museum staff \\
\hline 9 & Female & $41 \mathrm{yrs}$ & Germany & Museum staff \\
\hline
\end{tabular}

Fig. 1. Documentation template used for contextual interviews and brief profiles of visitors

processes of attention involved in the interpretation of labels [3], the exhaustive study on environmental psychology in museums and the methodology for visitor study has been extremely helpful to us in the current research [4].

\section{Methodology}

Considering the vast number of visitors that visit the museum every day, we decided to adopt three pronged methodology (Visitor Centred Design approach) as under-

- Contextual interviews of museum visitors (Reasoning and explanation)

We carried out contextual interviews [2] of visitors belonging to different age groups, genders and geographic locations and nationalities to understand their perception of the museum, informal learning outcomes and the reasons behind their response to the exhibits in terms of why they skipped certain objects or what intrigued them most.

- Visitor survey through questionnaire (Prominent trends)

Our objective of visitor survey was to get large sample of self-reports on common set of questions and collect statistical data. This was intended to help in analyzing the prominent trends of actual visitor experience.

\section{- Visitor behavior study (Social behavioral patterns)}

Study of visitor behavior in museums was intended to observe their spontaneous reactions to antiquities and the museum environment. We also intended to notice the social behavioral pattern of visitors and the interactions between groups.

Above activities were not carried out in an exact sequential order but it overlapped sometimes and gave us the opportunity of improvisation wherever applicable based on the incoming insights. This research was primarily carried out at Raja Dinkar Kelkar Museum, Pune, India and some observations were also made at Prince of Wales Museum, Mumbai, India. Overall, about 100+ museum visitors participated in our study.

\section{Contextual Interview}

A total of 12 contextual interviews were conducted to find out the various layers of visitors' experience. The interviews were conducted like a talk while moving across 
the museum galleries. A typical interview lasted for about 25 minutes to 100 minutes. 9 of these interviews were good enough and were interpreted thoroughly. The interpretation was done on the same day after finishing the interview.

An age group of roughly about 15 to 30 years was chosen because it was observed that majority of the youth is comparatively less interested in visiting a museum as against going to movies, hanging out or having fun with friends. The youth have had fair enough exposure to the world and can form their opinions; they are more critical in their approach and hence a lot of problems could be identified.

The visitors' responses were classified as visitor statements, observations, cultural influences, breakdowns, design ideas and insights. These responses were rated as high, medium or low as per the interview focus. All interviews were compared and affinity found across the age group.

\section{Survey of visitors}

Questionnaires in English and Marathi languages (the museums have significant amount of regional visitors) were kept at the exit lobby of the museum and the visitors were requested to fill them. The questionnaire was designed to gather specific data from the visitors. Help was given to those who did not know either of these languages. The main focus of the survey was to find out the-

- Demographic and basic information about visitors

- Appreciation levels of different visitors

- Crucial aspects in the presentation of artefacts
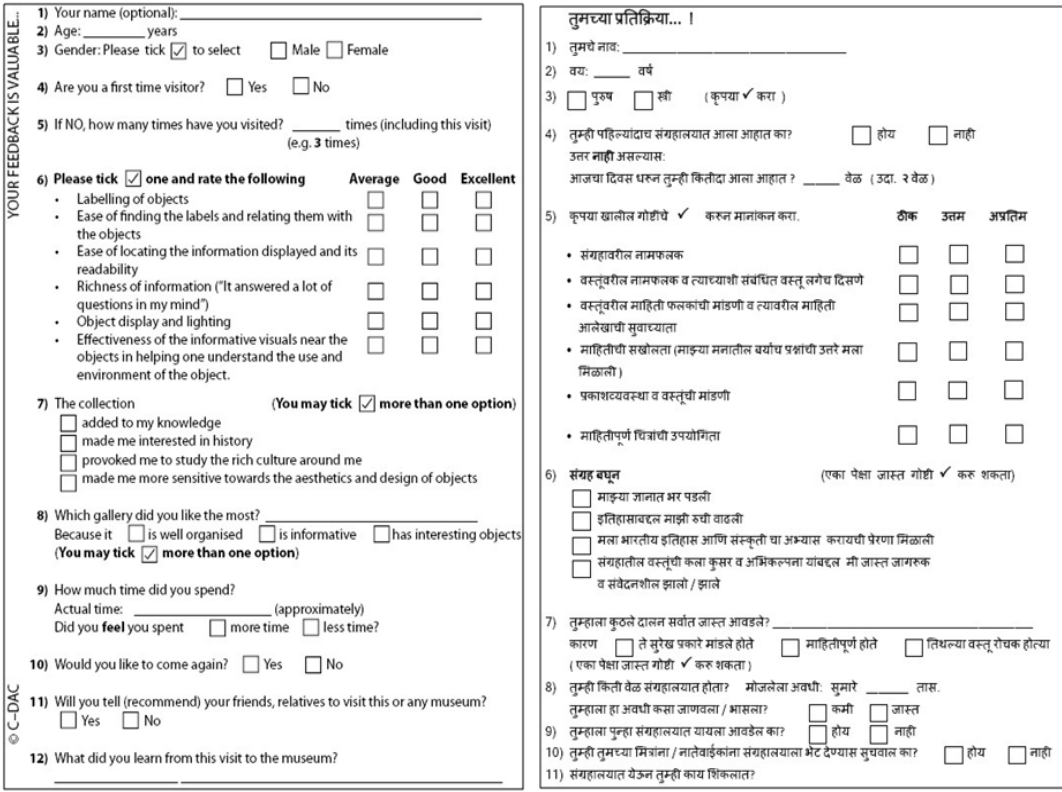

Fig. 2. A. Survey forms designed in English and Marathi languages 
- Likings and interests of different visitor groups

- Value addition to the visitors

- Time spent by the visitors

Some of the survey findings are explained below.

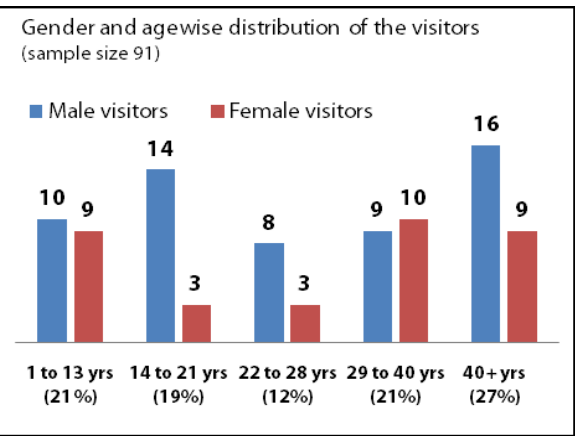

A

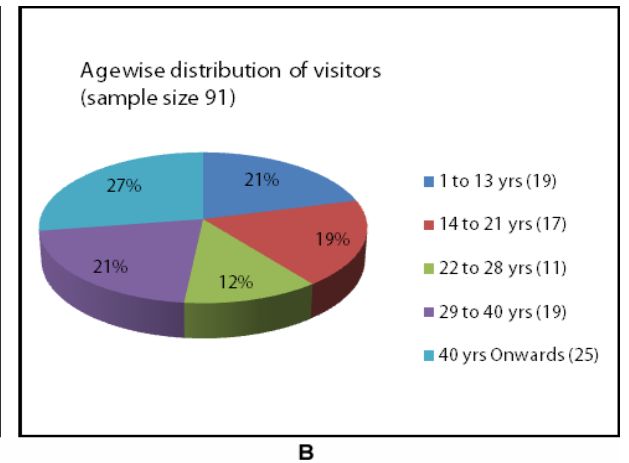

B

Fig. 3. A. Gender and agewise distribution of visitors B. Agewise distribution of visitors

\subsection{Visitor Demographics}

As shown in figure 3A, more number of female visitors in the 29-40 yrs age group indicates that more mothers (or more families) have accompanied their children to the museum. A large number of male visitors in the 14 to 21 years age group indicate groups of friends or travelers.

The number of children ( 1 to 13 yrs) and mostly parents (29 to 40 yrs) is almost the same throughout the total sample size of 91 . This indicates the following possibilities:

- Only one of the parents (either father or mother) has filled up the form.

- There are probably visitor groups in majority like: child accompanied only by the mother / child accompanied only by the father.

Figure 3B shows that there is less number of visitors in the age groups of 14 to 28 years. It is perhaps due to lack of interest in museums or increased academic load on the students and professional commitments for those employed. There is greater number of visitors in the age groups of 29+ and below 13 years. It again confirms that these are mostly the children accompanied by parents or elderly persons.

\subsection{Value Addition to the Visitors}

As shown in figure 4, the maximum 'NO' replies came from the 22 to 28 yrs age group. This indicates that special attention and strategies need to be developed to cater to this group. Also, more 'NO' responses were registered for the collection 'Provoked me to study...' \& 'Made me more sensitive....' 


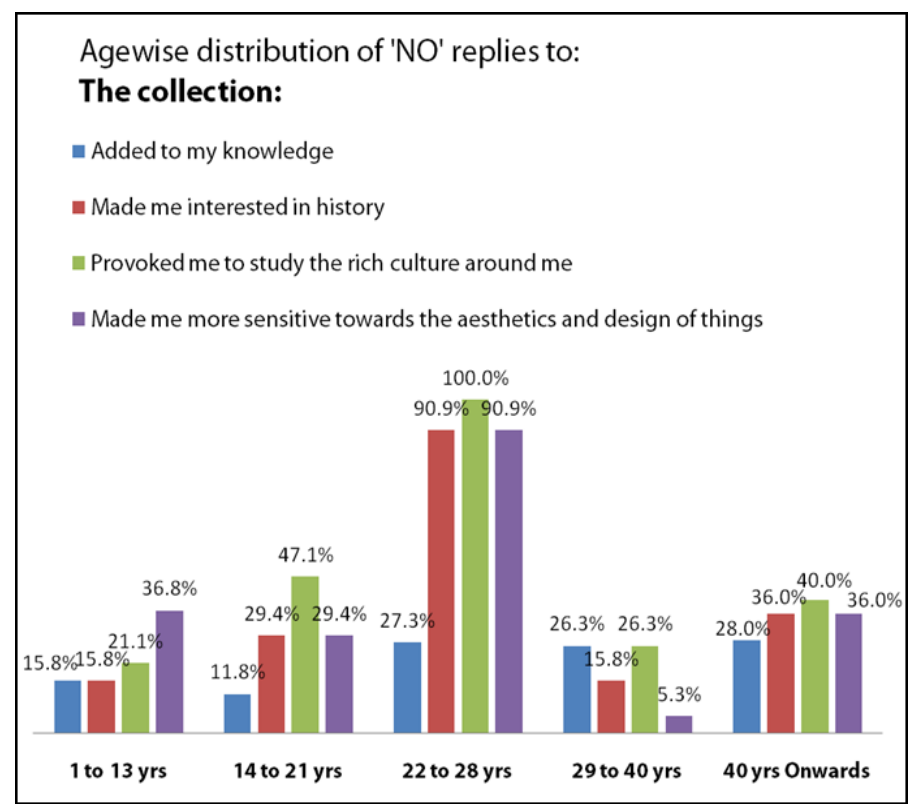

Fig. 4. Age wise distribution of 'NO' replies to the overall experience of 'The collection...'

\subsection{Time Spent by Visitors}

Our statistical study shows that individuals in the 22 to 28 yrs age group spent significantly less time in the museum if compared with the visitors in other age groups. It indicates that the artefacts could not engage them for longer time.

\section{Visitor Behavior Observations}

The behavioral study of visitors in museum environment revealed certain patterns in terms of their response to the artefacts such as expressions, gestures and postures, interactions between the group members and social behavior. We were able to identify following prominent social groups among the museum visitors-

- Parents \& children

- Grandparents, parents and children

- Friends (teenagers and youth mostly)

- Teachers and schoolchildren

- Families and their relatives or guests

- Domestic Tourists

- Foreigners

- Others (loners, people visiting from nearby places, etc...) 
The visitors are further categorized based on their interest levels-

- Motivated - those who visit museum out of interest e. g. tourists

- Initiated - those who are guided by somebody e.g. children

- Non-initiated and non-motivated - those who came to kill time

Relevant observations of visitor / social behavior are given in the deliberation on cognitive needs of visitors below.

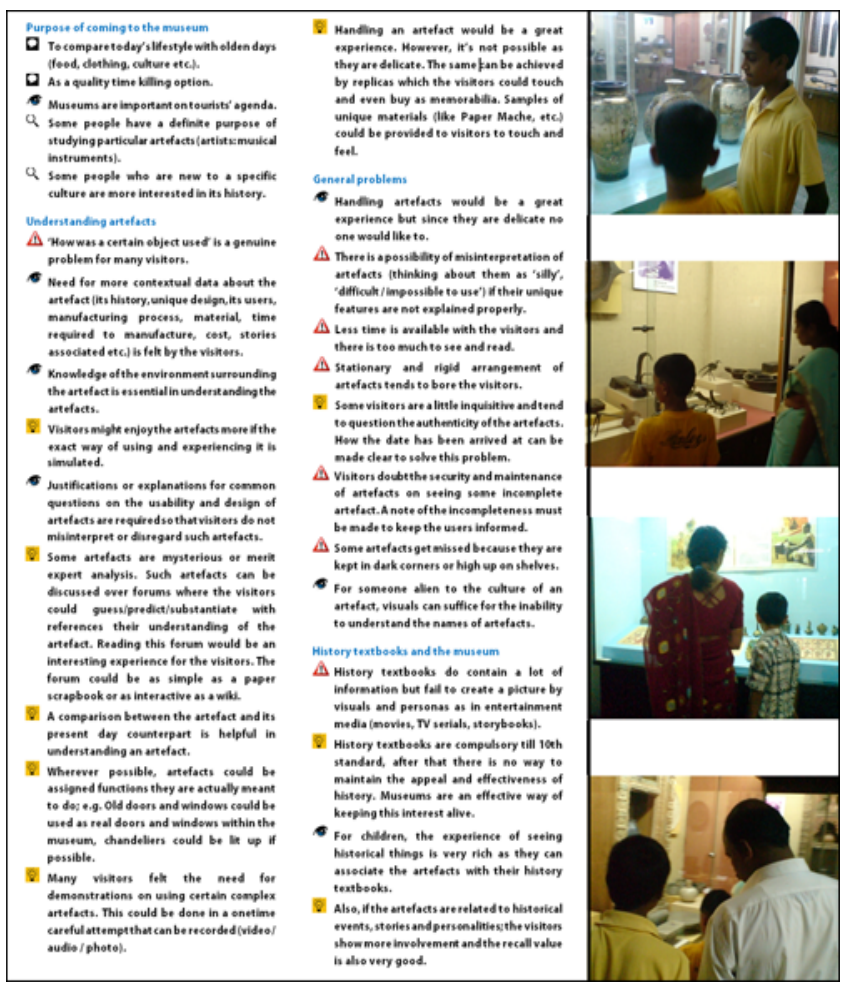

Fig. 5. Sample documentation of visitor interviews marked as User statements, Observations, Insights, Design idea / Recommendation, Breakdowns / Concerns, etc along with the photographs of museum visitors

\section{Cognitive Needs of Visitors}

The contextual interviews, visitor survey and behavioral observations together have put forth various cognitive needs of visitors that remain unaddressed in the present museum settings. The proposed interactive kiosk software must be designed to cater to the following cognitive needs of museum visitors. It is possible to develop functionalities, features, interaction templates and user interface design based on the cognitive needs of visitors. 


\section{- Curiosity about the non-visible parts of artefacts}

Most of the artefacts in the museum are kept in protected displays and restricted areas. The visitors are compelled to view the artefacts from certain distance with a fixed view point. Although these restrictions are essential for the safety of artefacts, they put major constrains on the visitors in developing full understanding of artefacts. Furthermore, some artefacts need to be seen from a closer distance using a magnifying glass; and some artefacts need to be opened for viewing the internal details. Due to restrictions, this curiosity about 'what is inside? or what is on the other side of object?' is never satisfied.

\section{- Comparison with old and modern lifestyle}

Human mind is habitual to making comparisons and forming semantic associations and relationships between different things. Many times the artefacts are very culture specific that are very difficult to identify in terms of its purpose and use. We found that visitors appreciate more when they are able to form comparisons between the historical objects and modern objects. Figure 6 shows the prototype of an interactive application meant to trigger comparative thinking about modern and Indus civilization objects.

\section{- Visualization of oneself using the artefacts}

Visitors are often noticed making gestures to imagine themselves holding the sword displayed in the exhibits or any other object for that matter. One desires to wear the costumes or ornaments from ancient period. One wants to try using the ancient artefacts. But such desire always remains unfulfilled due to the restricted museum environment.

\section{- One-click-one-toffee approach for narrow attention span}

We have observed that most visitors have no patience to read elaborate historical information displayed as posters in museums. They tend to have a very limited attention span. Therefore, smaller nuggets of knowledge that can be absorbed in one glance should be presented in the kiosks. It will also reduce the chances of crowding over the kiosk. We would like to call this approach as 'one-click-one-toffee approach'. It implies that we quickly provide a stimulating and memorable piece of information which can be understood quickly.

\section{- Stories associated with the artefacts}

Visitors are rarely interested in the dates and historical descriptions of artefacts. What interest them most are stories, drama, performances and the thrill of being witness to certain historical events in their imagination. This is evident from the fact that although the museums are not so popular among the youth but the historical films are.

\section{- Shared cognition between various social groups}

We found that large number of museum visitors come in groups as mentioned in section 4. The group invokes significant social interaction in response to the museum artefacts. Visitors discuss, explain and share their point of views and knowledge while looking at the museum artefacts. Through collective efforts they try to develop greater understanding about the artefacts. 


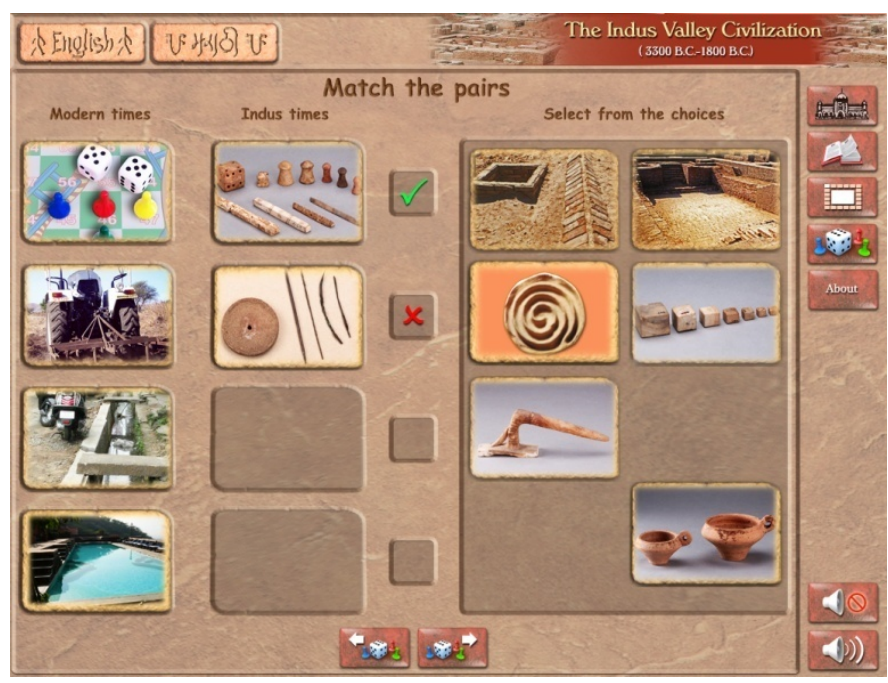

Fig. 6. Prototype of an interactive game in which one can match the pairs of objects from 'Modern Times' and 'Indus Times'. It is meant to provoke comparison of lifestyles in the minds of museum visitors. The game presents shuffled examples of dice, toys, plough, spindle and needles, cup, bath, drainage system etc from the modern era and from the era of Indus civilization for comparison. The visitor has to find the matching pairs.

The interactive kiosk is conventionally assumed to be used by one user at a time. To further encourage the social interaction and shared cognition process simple games and puzzles could be designed that allow inputs from 3 to 4 persons in a group.

\section{- Holistic experience of artefacts}

In summary, we can say that the museum visitors are deprived of the aspects essential to develop overall cognition of artefacts and the experience of it. They are unable to visualize as the artefacts are usually disconnected from its original environment and the context where they belonged. The descriptive posters and panels in museums fail to fill up the absence of experiential elements. The textual information needs to be read, interpreted and comprehended by visitors who have a very limited attention span.

\section{- Inarticulate cognitive map of museum's architecture}

During our contextual interviews, visitor surveys and behavioural study, we found that many visitors want to visit only the important artefacts or galleries due to time constraints. In such situation, they are unable to develop a proper cognitive map of the architectural layout of galleries in museums. The reference of their present location in the museum vis-à-vis the static maps displayed on walls do not help in understanding the navigational path to various galleries, especially when one wants to quickly visit only the selected galleries and artefacts.

We have been able to convert some of the cognitive needs of museum visitors into interactive games and features as shown in Table 1, to help in the visualization of Indus civilization. The demonstration of working prototypes of these possibilities has generated extremely positive feedback from visitors and museum officials both. 
Table 1. Interaction design based on the cognitive needs of museum visitors

\begin{tabular}{lll}
\hline \multicolumn{4}{c}{ Interaction design based on cognitive needs of museum visitors } \\
\hline 1 & $\begin{array}{l}\text { One-click-one-toffee approach } \\
\text { Comparison between old and }\end{array}$ & $\begin{array}{l}\text { Visual index with layered information } \\
\text { Interactive Game: Match the pairs between } \\
\text { modern and Indus lifestyle }\end{array}$ \\
3 & $\begin{array}{l}\text { modern lifestyles } \\
\text { Visualization of oneself using the } \\
\text { artefacts }\end{array}$ & $\begin{array}{l}\text { Interactive animation of toy-cart from Indus } \\
\text { valley }\end{array}$ \\
4 & $\begin{array}{l}\text { Multisensory experience of places, } \\
\text { environment and the context }\end{array}$ & 3D Visualization of Indus townscape \\
Visualization of oneself using the & Interactive re-construction of a broken vase \\
artefacts
\end{tabular}

\section{Content Selection Parameters}

As stated earlier, we have a constraint that each interactive application should engage the visitor for not more than $20 \mathrm{mnts}$ if (s)he was to go through all the information, so as to avoid crowding before the kiosk. Each museum gallery displays hundreds of artifacts therefore we need to apply certain parameters to select the artifacts for inclusion in the interactive kiosk software. Following parameters are evolved based the cognitive needs of visitors -

Artefacts that -

- $\quad$ have interesting features which are not visible due to fixed view

- $\quad$ have significant multisensory attributes

- have potential for presenting comparisons between 'then' and 'now'

- $\quad$ visitors like to imagine themselves using it

- $\quad$ inspire one to visualize the lifestyle or which can be better understood with the context

- $\quad$ have interesting stories associated with them

- explain information useful in the educational context

- provoke group interaction / discussions

- $\quad$ are popular due to historical significance and other specialties like craftsmanship, aesthetic value, etc.

Artefacts complying with above parameters can be selected for inclusion in the kiosk software.

\section{Conclusion}

The interactivity, animations and multimedia capabilities of kiosk software must be focused on overcoming the access restrictions and constraints of museums. It creates several opportunities to design interactive games, puzzles, presentation of stories, etc. It will also be possible to demonstrate the use of objects and visualization of ancient lifestyles with interactivity.

The contextual interviews, survey and behavioral observations of museum visitors have been extremely helpful in identifying their cognitive needs, which remain 
unaddressed in the present museum settings. The cognitive needs of museum visitors are identified as under-

- Curiosity about the non-visible parts of artefacts

- Multisensory perception of artefacts

- Comparison with old and modern lifestyle

- Visualization of oneself using the artefacts

- One-click-one-toffee approach for narrow attention span

- $\quad$ Stories associated with the artefacts

- Shared cognition between various social groups

- Inarticulate cognitive map of museum's architecture

- Holistic experience of museum artefacts

- Overcome all the points of cognitive deprivation

Proposed interactive kiosk software must be designed based on the cognitive needs of museum visitors in order to offer higher level of learning and engaging user experience.

The content selection parameters are also largely based on the points where the visitor experience is compromised the most as elaborated in section 6.0.

\section{Acknowledgements}

We would like to acknowledge the cooperation and support provided by Prince of Wales Museum, Mumbai; Raja Dinkar Kelkar Museum, Pune and Human-Centred Design and Computing group of C-DAC, Pune, India.

\section{References}

1. Allen, S., Gutwill, J., Perry, D., Garibay, C., Ellenbogen, K., Heimlich, J., Reich, C., Klein, C.: Research in Museums: Coping With Complexity. In: Falk, J., Dierking, L., Foutz, S. (eds.) In Principle, In Practice: Museums as Learning Institutions, ch. 16. AltaMira Press (2007)

2. Beyer, H., Holtzblatt, K.: Contextual design: defining customer-centered systems. Morgan Kaufmann Publishers Inc., San Francisco (1998)

3. Bitgood, S.: The role of attention in designing effective interpretive labels. Journal of Interpretation Research 5(2), 31-45 (2000)

4. Bitgood, S.: Environmental Psychology in Museums, Zoos, and Other Exhibition Centers. In: Bechtel, R., Churchman, A. (eds.) Handbook of Environmental Psychology, pp. 461480. John Wiley \& Sons, Chichester (2002)

5. Czyzewicz, S.: Personalizing the visitor experience with dynamic information systems. Journal of Computing Sciences in Colleges 20(5), 124-125 (2005)

6. Damala, A., Cubaud, P., Bationo, A., Houlier, P., Marchal, I.: Bridging the gap between the digital and the physical: design and evaluation of a mobile augmented reality guide for the museum visit. In: Proceedings of the 3rd international conference on Digital Interactive Media in Entertainment and Arts, pp. 120-127 (2008)

7. Hornecker, E., Stifter, M.: Learning from interactive museum installations about interaction design for public settings. In: OZCHI 2006, pp. 135-142 (2006) 
8. Hope, T., Nakamura, Y., Takahashi, T., Nobayashi, A., Fukuoka, S., Hamasaki, M., Nishimura, T.: Familial collaborations in a museum. In: CHI 2009: Proceedings of the 27th international conference on Human factors in computing systems, pp. 1963-1972 (2009)

9. Kelly, L.: Visitors and Learners: Adult Museum Visitors' Learning Identities. University of Technology, Sydney (2007)

10. Kules, B., Kang, H., Plaisant, C., Rose, A., Shneiderman, B.: Immediate Usability: Kiosk Design Principles from the CHI 2001 Photo Library. Tech. Report CS-TR-4293, U. Maryland (2003)

11. Mazzone, M., Horton, M.: Requirements for a multimedia museum environment. In: Nordic Conference on Human-Computer Interaction, vol. 82, pp. 421-424 (2004)

12. Wilson, T.D.: On user studies and information needs. Journal of Documentation 62(6), 658-670 (2006) 